\title{
A Simple Framework to Develop Pedagogical Augmented Reality Programs: an Application Based on Plants Teaching
}

\author{
Ludovic Hamon, Emmanuelle Richard, Paul Richard and Jean-Louis Ferrier
}

ISTIA, 62 avenue Notre Dame du Lac, 49000 Angers,France

\begin{abstract}
An augmented reality Engine for the Construction of Pedagogical Applications (ECPA) is presented with an ECPA menu composed of two (master and slave) sub-menus as the main interface. With simple LUA scripts that allow building the application features, ECPA can be used to easily program different educational applications in a short time. To illustrate the possibilities of ECPA engine, an application called Virtual Plant For Children (VPFC) is created. VPFC allows young people to interact with virtual plants thanks to an interactive $L$-system for plants growing simulation. A usability test is made to validate our interface and interaction method, in which twenty-four K4-K5 children are instructed to make virtual plants grow by giving them water, heat and light.
\end{abstract}

Index Terms - Augmented reality, interaction techniques, interactive $\mathbf{L}$-system, virtual plants.

\section{INTRODUCTION}

According to Johnson et al., it is generally argued that the affective factor, encompassing interaction and engagement, is one of the most important advantages that Virtual Reality (VR) and by extension Augmented Reality (AR), have to offer to education [1]. Biological systems require complex modeling that are not adapted to interactive real-time applications. However, up to now, very few VR applications have been dedicated to botany learning $[1,2]$. A relevant example proposed by Johnson et al., the NICE project, offered an immersive environment for children, but required intrusive interfaces, and expensive cumbersome equipment that did not fit with a classroom context. Another interesting example was the Garden Alive system by Teajin and Woontack. By mixing a real garden and a virtual garden, and using some detection sensors and tangible interfaces, that system was an adapted solution in terms of efficiency and realism but not in terms of low cost and easy/reusable installation. AR applications using fiducial markers like ARToolkit [3] can give non intrusive interfaces with both semi tangible artefacts and a manipulable representation of a 3D conceptual abstraction in the real world. And, L-system created by Lindenmayer in 1968 [4], is a parallel rewriting system generating virtual plants with very realistic morphological and physiological aspects.

Manuscript Received on 4 October 2010

E-mail:ludovic.hamon@etud.univ-angers.fr.
This paper presents a generic AR Engine for the Construction of Pedagogical Applications (ECPA) to easily develop different programs for a classroom context in particular. A first application called Virtual Plant For Children (VPFC) is developed in which children interact with real time virtual plants generated by our own L-system engine called Real-Time Interactive L-system (RTIL-system).

In section 2, a short survey about interaction methods used in AR educational applications is presented. The third section presents the ECPA engine and the ECPA menu. The construction, implementation and features of VPFC and RTIL system are described in section 4 . Section 5 is dedicated to the description and results of a usability test of our interface and interaction method. The objectives are (i) to validate this low cost and non intrusive interface, in terms of usability (ii) to check if the VPFC time game fits with a classic time for a computer initiation session in school, and (iii) finally to investigate children performance and behavior during interaction with the virtual plants. Finally, the conclusion provides some perspectives and future works.

\section{RELATED WORKS}

\subsection{Interaction Techniques Used In Augmented Reality Applications For Education}

Several learning AR systems have been developed in various domains. In the field of the weather sciences, Kim showed principles that form rain and clouds [5] and induced user's participation by modifying markers position. In their application for learning Korean language, Jung and Lee worked on the arrangement of building blocks called "jamo" and used an AR buttons system to play sounds, display the phonetic signs or construct words images [6].

AR was also used for younger children's storytelling [7]. Dünser and Hornecker investigated literacy education using an AR interactive book [8]. Pages and paddles were both covered with AR markers. Story events could be triggered by placing paddles close to specific spots. Grasset et al. used the same interaction method and added visual and auditory enhancements to an already published history [9]. Events triggering could also be done by gazing at a specific augmented element in the book with a camera. ZhiYing and Cheok proposed an innovative system based on two cubes with 
markers in a storytelling context too [10]. The virtual items brought close together could trigger events depending of the story scene.

A mathematical educational application that used a system inspired by the previously cited "cubes" was developed by Lee et al. [11]. The game is based on a board that displayed an AR scenario using multiple markers. So, the system could augment virtual images even though few markers were masked.

In the field of chemistry education, Almgren et al. proposed an interesting approach for teaching molecular structures [12]. Augmented Chemistry was an application based on ARToolkit where an augmented gripper is used to pick up periodic table element and add them to the molecule.

For biology, Nischelwitzer et al. proposed an augmented book that allows users to learn about the human digestive system. The book is configured as a multi-marker page to avoid covering [13].

A relevant work appeared in the plant domain in 2008 [14]. Oh and Woo presented an AR system that allowed children to interact with a garden of flowers using a learning companion. A mobile computer attached with a camera that gazed at a book with markers displayed a virtual animated flower and virtual factors (water, light, and fertilizer). A special marker called controller allowed user to select a factor and apply it to the flower by getting closer. The augmented flower showed several predefined changes such as growing up, withering, and waving.

In other way, Gilroy et al. [15] described an Augmented Reality Art installation based on ARToolkit. A virtual tree, defined by an L-system and influenced by the perceived negative/positive emotional state of the spectators, grew/faded on a fiducial marker. L-system parameters took into account, were color, branching, speed of growth and branches orientations. Unfortunately the process that allows parameters change in real time on this kind of interactive L-system is not described.

\subsection{Discussion About AR Interaction Methods}

Considering only interactions that lead to relevant changes on the game scenario, moving a marker to other fiducial markers or to key locations is the most commonly used method $[5,7,8,9,10,12,14]$. This kind of interaction arises user engagement, but some issues remain. Indeed, with system similar to ARToolkit, the marker detection is confronted to the covering problem. Manipulating those ficudial markers without covering the key detection symbols is not trivial. To avoid this, some solutions exist like the use of paddles, or other solid extensions that separate the hand spatial zone from the marker spatial zone $[8,9,10,12,14]$. Another solution is to increase the number of markers for one displayed object $[11,13]$. These previous methods do not offer a perfectly effective solution, but marker covering can be the lead advantage of an interaction based on button concept [6]. Moreover menu systems are often used for common devices such as dispenser/mobile device/computer game/television/electronic devices....

An AR menu system is designed for the main interaction method of ECPA using fiducial markers as a simple and tangible interface for children.

\section{ECPA ENGINE AND ECPA MENU}

The application set-up is illustrated in Fig. 1(a). An interactive menu was designed using fiducial markers placed on desk in front of the user. A Logitech QuickCam Pro 9000 placed on the top of a flat HD screen was used for the acquisition of the video signal.

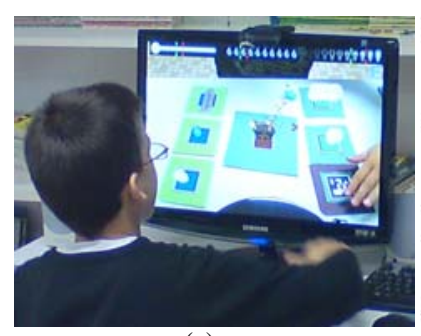

(a)

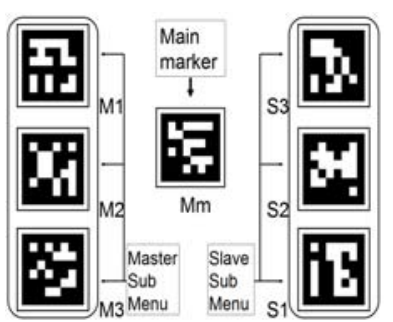

(b)
Fig. 1. (a) A 10 year old boy interacting with a virtual plant generated by RTIL-system, (b) Fiducial markers disposition on desk

\subsection{ECPA System Description}

The application was developed in $\mathrm{C} / \mathrm{C}++$ and consisted of several non editable elements: a Collada loader for 3D objects loading (DAE format), a graphical interface engine based on CeGUI (Crazy Eddie’s Graphical User Interface (GUI)), and a Fmod engine to play sounds. Our ECPA main engine is based on ARToolKit+, DirectShow for pattern detection, recognition and tracking and OpenGL library for 3D displayed objects. A LUA engine interprets LUA scripts.

LUA language is used to edit, develop and control the application that consists of several LUA scripts. LUA language does not need to be compiled, and every LUA script contains simple instructions that the developer needs to write or adapt.

Fig. 2 shows the ECPA engine and the files dependency diagram. The 3D objects (respectively sounds, 2D images) can be loaded and identified with the LUA EcpaCollada

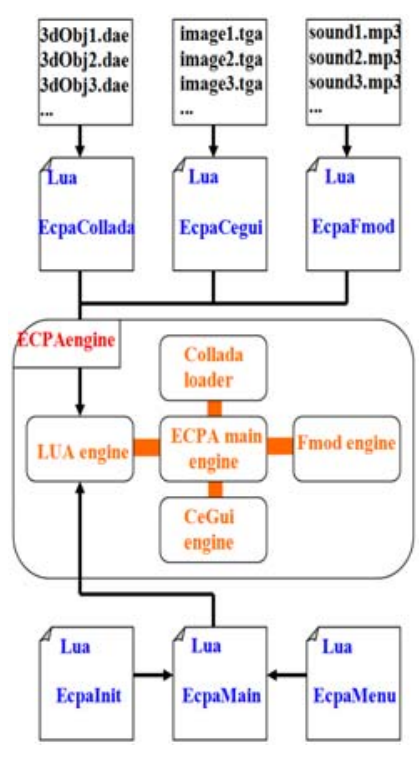

Fig. 2. ECPA engine and files dependency diagram

(respectively EcpaFmod, EcpaCeGui) script. Initialization of various parameters, as the GUI elements position can be done 
thanks to the LUA EcpaInit file. LUA EcpaMain file is the main script defining the global scenario behavior, based on the interactions made with the ECPA menu. The ECPA menu system is implemented and can be completely edited with the LUA EcpaMenu script.

\subsection{ECPA Menu Description}

The ECPA menu is composed of seven fiducial markers where virtual objects can be displayed. The studied object is placed on a main marker $(\mathrm{Mm})$ and two sub-menus, composed of three markers' each are added on both sides of the main marker: a master sub-menu (markers M1, M2, M3) and a slave sub-menu (markers S1, S2, S3). The markers disposition on desk is presented in Fig. 1(b).

Each functionality of the menu is triggered by masking with hand the corresponding marker for more than $0.8 \mathrm{sec}$. The markers of the master sub-menu and the main marker allow changing the slave sub-menu functionalities (f1 ,f2, f3, f4) and displayed objects. Using the slave sub-menu markers, the user can trigger a relevant action (i.e. an action on the game scenario). The ECPA menu composed of seven fiducial markers, allows the deployment of a matrix containing twelve features (4 functionalities (f1 , f2, f3, f4) x 3 markers (S1, S2, S3)). The automaton relative to the activation of slave submenu functionalities either by the master sub-menu, or by the main marker is presented in Fig. 3.

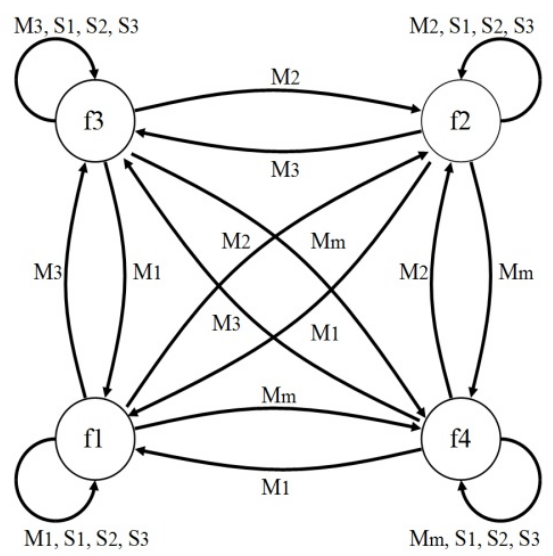

Fig. 3. Finite state automaton of the slave sub-menu.

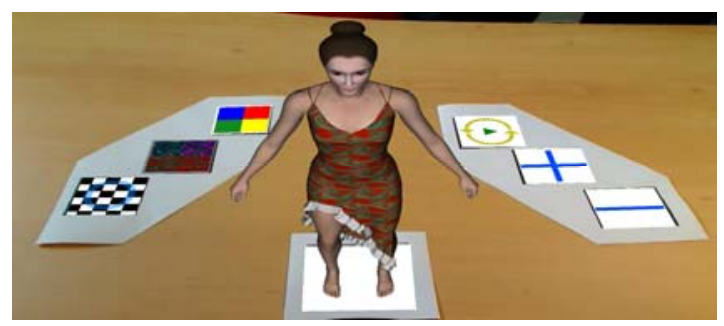

Fig. 4. Initiation of a child to simple clothing design.( Color Plate11 )

To illustrate ECPA menu, the works of Naud et al. [16] were adapted and simplified to fit with the ECPA engine (Fig. 4).

The application purpose was to allow children change the textures, the colors and the materials on the virtual model clothes positioned on the main marker [16]. The slave submenu functionalities according to the covered master sub-menu marker or the main marker are (Fig. 5):

- $\quad \mathrm{f} 1$ : application of a color among 3.

- $\quad \mathrm{f} 2$ : application of a texture among 3.

- $\quad \mathrm{f} 3$ : application of a material among 3.

- $\quad$ f4 : change size of the model or rotate the model.

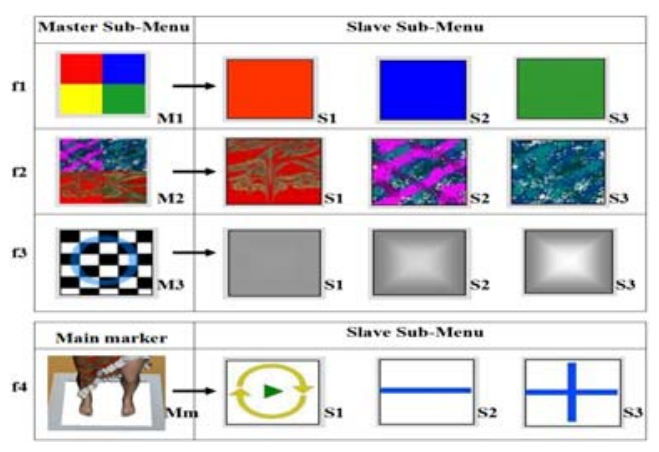

Fig. 5. AR clothing design: Illustration of the functionalities of the slave sub-menu activated from the master sub-menu and from the main marker.

\section{VIRTUAL PLANT FOR CHILDREN}

Virtual Plant For Children (VPFC) is developed with the ECPA engine. Two game modules are proposed. An introduction module where children can initiate themselves with the ECPA menu, and a main module that allows children interact with a dynamic virtual plant created with RTIL-system. This last one can grow and react in real time according to three needs (water, heat, and light), brought by the child, thanks to the ECPA menu.

\subsection{Real Time Interactive L-system}

In a previous paper, some works about interactive L-system were reviewed [17]. We highlighted that existing L-system were limited either in human interaction or modeling terms. Furthermore, few of them are open source. Our own L-system engine was developed and called Real Time Interactive L-system (RTIL-system). RTIL-system is a library written in $\mathrm{C} / \mathrm{C}++$ language that allows generating a 3D rendering of virtual plants and fractals based on Cpfg concept and model [17]. It offers interactive properties on the graphical representation with the corresponding modification on the L-system data structure called L-string, and data transmission and reception with environment/user thanks to dedicated communication functions and procedures. RTIL-system engine was added in ECPA engine for the VPFC application creation.

\section{2 ЕСРA Menu Description}

Three virtual objects are used as metaphors of some plants needs: a thermometer (M1) for heat, an electric bulb (M2) for light, and a drop of water (M3) for water (Fig. 6). These objects are displayed on the master sub-menu markers. The main marker (Mm) is used to display the virtual plant in a flower pot.

The slave sub-menu functionalities according to the covered master sub-menu marker or the main marker are the following 
ones (Fig. 6):

- $\quad$ f1 : add a big amount (S1)/a small amount (S2)/remove a small amount (S3) of heat.

- $\quad$ f2 : add a big amount (S1)/a small amount (S2)/remove a small amount (S3) of light.

- $\quad$ f3 : add a big amount (S1)/a small amount (S2)/remove a small amount (S3) of water.

- $\quad$ f4 : validate (S3)/cancel (S2) the answer or rotate the plant (S1).

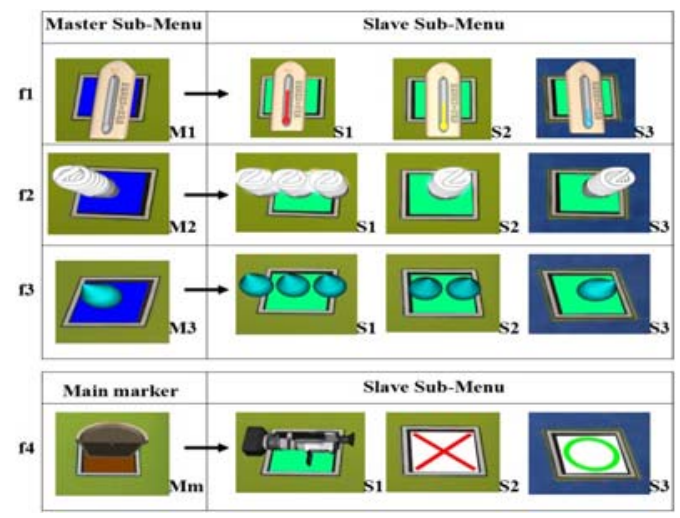

Fig. 6. VPFC: Illustration of the twelve features of the slave sub-menu activated from the master sub-menu and from the main marker.

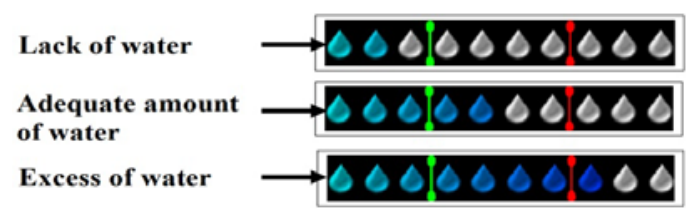

Fig. 7. Predefined intervals (green limit for minimal value and red limit for maximal value) for water.

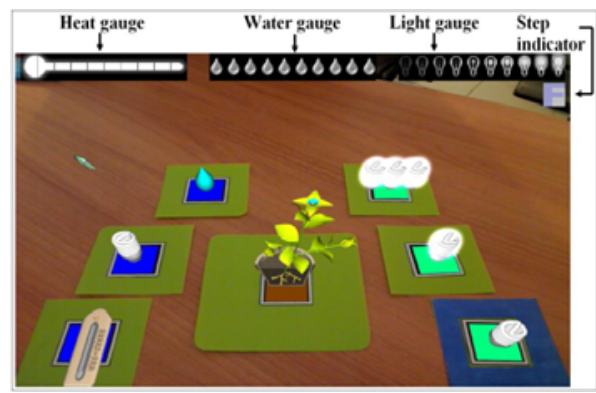

Fig. 8. Screen shot of the RTIL virtual plant module.

In order to help the child to correctly feed the virtual plant, a graphical user interface with three gauges that fill up according to the user interactions are displayed at the top of the window (Fig. 8). For each of the three needs, some predefined intervals (green limit for minimal value and red limit for maximal value) have been implemented for each stage. When the user validates the selected quantities by firstly covering the main marker (Mm) and then the green circle (S3) (Fig. 6), the virtual plant evolves throughout its life cycle state if the amounts are included in the predefined intervals (Fig. 7).

\subsection{Introduction Module}

The answers are given i.e., the minimal (green limit) and the maximal (red limit) required amounts of light, water and heat for the current step are displayed on the three gauges. Eight 3D static beans were drawn under 3DS max software, representing bean evolution from the seed state to the fruition state. Each 3d model is displayed successively on the main marker (Mm) when a correct reply of the previous bean state is validated.

\subsection{Main Module}

This RTIL virtual plant, inspired by the virtual rosebush L-system model developed at Agro-Campus Ouest Angers, is based on a parametric D2L-System [18].

The elementary modules are seed, root, inter-node, apex, bud, leaflet, peduncle, sepal, petal, flower and fruit. Linear functions are used to make evolve the parameters of each module like (component length, number of internodes, angles, colors, branching, etc). The graphical representation is composed of a primary stem with leafs and a blue flower, and three sub order stems with leaves and a colored (red, yellow and purple) flower at each extremity (Fig. 9(f)).

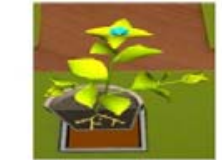

(a)

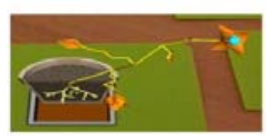

(d)

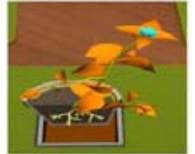

(b)

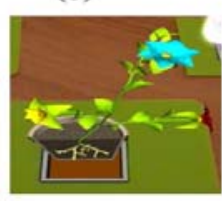

(e)

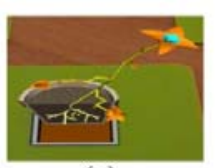

(c)

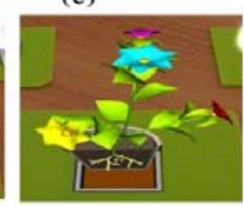

(f)
Fig. 9. Illustration of a possible evolution of the virtual plant (a) at its flowering stage: a lack of water and excess of heat (b,c,d) followed by a correct feeding $(e, f)$.

The evolution of this plant is divided into three stages: germination, growth and flowering. A letter is displayed to inform the child about the plant current stage (G: germination, $\mathrm{C}$ : growth and F: flowering (step indicator, Fig. 8)). At each stage, the child must give the correct amounts of water, light and heat, and validate its choices. The goal is to reach the end of the flowering stage. The corresponding L-system script uses two types of rules: positive rules that check in the logical condition (cf. [17]) if the heat, water, and light values are correct and negative rules that check the opposite. The RTIL virtual plant reacts to lack or excess of needs (i.e. changing colors, inappropriate angles between components, interrupted or bad growth, fall of leaves, etc...) and the process of evolution is fully reversible. For e.g., the RTIL virtual plant may reach the flowering stage after having drastically lacked needs as illustrated in Fig. 9.

The red and green interval limits appear only if the good amount of needs is brought to the plant. If the amounts are partially found (only one or two), red and green interval limits appear only on the gauges linked to the one or two good needs. The child must take into account the visual negative effects to 
correct their previous reply (cf. 5.1). Once the next stage is reached, interval values are changed, red limit and green limit disappear and gauges become empty.

\section{EXPERIMENTAL STUDY}

\subsection{Method}

To evaluate AR/VR systems, several methods are widely used like: user testing (1), heuristic evaluation with some experts (2), free inspection (3), and inspection with ergonomic criteria (4) [19]. Some issues can appear for (3) and (4) with some unfocused and/or unexperienced children for evaluation of complex criteria. The application was firstly tested by 3 experts of the domain and they all noticed the multi covering problem i.e. the fact of covering more that one marker at once and therefore to have some issues to trigger functionalities.

Furthermore, child's opinion must be taken into account. Thus, for this second inspection, a user testing was done. 24 K4-K5 children from the Saint-Antoine primary school in Angers (France) participated in the experiment (cf. Fig. 1(a)). They came in groups of 2 and were instructed to complete first the introduction module, then the main module. The experimenter gave to each child some explanations about the two modules goal and the interaction technique before the experiment. An assistance is provided only during the introduction module. Concerning the main module, six snapshots of the plant exhibiting excesses or lacks of each need (water, heat and light) were provided in order to help the child to correctly feed the plant. Task completion time associated with each module was recorded. In addition, observation during the experiment was done by the experimenter (Table 2). Once the child finished the experiment, he/she was asked to fill in a questionnaire about usability, enjoyment and his/her preferences (Table 1).

\subsection{Results And Analysis}

1) Task Completion Time:

The children took, in average, about $39 \mathrm{~min} .2 \mathrm{sec}$. to complete the experiment (STD : 8 min. $2 \mathrm{sec}$.). The mean task completion time associated with the introduction module is $15 \mathrm{~min} .25 \mathrm{sec}$. (STD : 3 min. 55 sec.). The mean task completion time associated with the main module is $23 \mathrm{~min}$. $36 \mathrm{sec}$. (STD : 5 min. $33 \mathrm{sec}$.). The maximum and minimum completion time are respectively: $22 \mathrm{~min}$. $25 \mathrm{sec}$. and $10 \mathrm{~min}$. $4 \mathrm{sec}$. for the introduction module, $34 \mathrm{~min}$. and $10 \mathrm{~min}$. $53 \mathrm{sec}$. for the main module, $55 \mathrm{~min} .58 \mathrm{sec}$. and $20 \mathrm{~min}$. $57 \mathrm{sec}$. for the whole game. Assuming that a classic time for a computer initiation session in school is at least one hour, it appears that the application time game could fit with a complete short lesson with additional pedagogical contents.

2) Application Usability:

According to the observations: concerning the interaction technique, 18 children quickly understood the functioning of the ECPA menu. Nevertheless, 6 children needed some further explanations. Concerning children effective performance, 15 children easily used the ECPA menu. 7 children needed a short
TABLE 1: PARTIAL DATA FROM THE QUESTIONNAIRE CONCERNING USABILITY, ENJOYMENT AND CHILDREN PREFERENCES.

\begin{tabular}{|c|c|c|c|c|c|}
\hline & \multicolumn{5}{|c|}{ Answers } \\
\hline & $\begin{array}{l}\text { very } \\
\text { much }\end{array}$ & much & average & $\begin{array}{l}\text { not very } \\
\text { much }\end{array}$ & $\begin{array}{c}\text { not at } \\
\text { all }\end{array}$ \\
\hline $\mathrm{a}$ & $\begin{array}{c}17 \\
(71 \%)\end{array}$ & $\begin{array}{c}6 \\
(25 \%)\end{array}$ & $\begin{array}{c}1 \\
(4 \%)\end{array}$ & $\begin{array}{c}0 \\
(0 \%)\end{array}$ & $\begin{array}{c}0 \\
(0 \%)\end{array}$ \\
\hline b & $\begin{array}{c}19 \\
(79 \%)\end{array}$ & $\begin{array}{c}3 \\
(13 \%)\end{array}$ & $\begin{array}{c}2 \\
(8 \%)\end{array}$ & $\begin{array}{c}0 \\
(0 \%)\end{array}$ & $\begin{array}{c}0 \\
(0 \%)\end{array}$ \\
\hline & $\begin{array}{l}\text { very } \\
\text { easy }\end{array}$ & easy & adequate & hard & $\begin{array}{l}\text { very } \\
\text { hard }\end{array}$ \\
\hline c & $\begin{array}{c}4 \\
(17 \%)\end{array}$ & $\begin{array}{c}11 \\
(46 \%)\end{array}$ & $\begin{array}{c}8 \\
(33 \%)\end{array}$ & $\begin{array}{c}1 \\
(4 \%)\end{array}$ & $\begin{array}{c}0 \\
(0 \%)\end{array}$ \\
\hline d & $\begin{array}{c}2 \\
(8 \%)\end{array}$ & $\begin{array}{c}3 \\
(13 \%)\end{array}$ & $\begin{array}{c}10 \\
(42 \%)\end{array}$ & $\begin{array}{c}9 \\
(37 \%)\end{array}$ & $\begin{array}{c}0 \\
(0 \%)\end{array}$ \\
\hline $\mathrm{e}$ & $\begin{array}{c}6 \\
(25 \%)\end{array}$ & $\begin{array}{c}10 \\
(42 \%)\end{array}$ & $\begin{array}{c}6 \\
(25 \%)\end{array}$ & $\begin{array}{c}1 \\
(4 \%)\end{array}$ & $\begin{array}{c}1 \\
(4 \%)\end{array}$ \\
\hline & $\begin{array}{l}\text { too } \\
\text { short }\end{array}$ & short & adequate & long & $\begin{array}{l}\text { too } \\
\text { long }\end{array}$ \\
\hline$f$ & $\begin{array}{c}0 \\
(0 \%)\end{array}$ & $\begin{array}{c}4 \\
(17 \%)\end{array}$ & $\begin{array}{c}19 \\
(79 \%)\end{array}$ & $\begin{array}{c}1 \\
(4 \%)\end{array}$ & $\begin{array}{c}0 \\
(0 \%)\end{array}$ \\
\hline $\mathrm{g}$ & $\begin{array}{c}1 \\
(4 \%)\end{array}$ & $\begin{array}{c}1 \\
(4 \%)\end{array}$ & $\begin{array}{c}11 \\
(46 \%)\end{array}$ & $\begin{array}{c}11 \\
(46 \%)\end{array}$ & $\begin{array}{c}0 \\
(0 \%) \\
\end{array}$ \\
\hline h & $\begin{array}{c}\text { yes } \\
2 \\
(8 \%)\end{array}$ & $\begin{array}{c}\text { no } \\
22 \\
(92 \%)\end{array}$ & & & \\
\hline
\end{tabular}

Questions:

a: do you enjoy the introduction module?

b: do you enjoy the main module?

c: do you think the introduction module is ... ?

$\mathrm{d}$ : do you think the main module is ... ?

$\mathrm{e}$ : according to you, the ECPA menu is . . . to use ?

$\mathrm{f}$ : do you find the time for the introduction module ... ?

g: do you find the time for the main module. . . ?

h: did you play a AR game before ?

TABLE 2: PARTIAL DATA FROM THE OBSERVATION EXPERIMENTER'S GRID CONCERNING CHILDREN CONCENTRATION, BEHAVIOR AND MASTERING LEVEL OF THE GAME AND THE ECPA MENU.

\begin{tabular}{|c|c|c|c|c|}
\hline & \multicolumn{4}{|c|}{ Observation results } \\
\hline & $\begin{array}{l}\text { at the } \\
\text { beginning }\end{array}$ & $\begin{array}{c}\text { with a } \\
\text { short } \\
\text { adaptation } \\
\text { time }\end{array}$ & $\begin{array}{c}\text { with a } \\
\text { long } \\
\text { adaptation } \\
\text { time }\end{array}$ & never \\
\hline a & $\begin{array}{c}18 \\
(75 \%)\end{array}$ & $\begin{array}{c}5 \\
(21 \%)\end{array}$ & $\begin{array}{c}1 \\
(4 \%)\end{array}$ & $\begin{array}{c}0 \\
(0 \%)\end{array}$ \\
\hline b & $\begin{array}{c}15 \\
(62 \%)\end{array}$ & $\begin{array}{c}7 \\
(30 \%)\end{array}$ & $\begin{array}{c}1 \\
(4 \%)\end{array}$ & $\begin{array}{c}1 \\
(4 \%)\end{array}$ \\
\hline & often & sometimes & never & \\
\hline $\mathrm{c}$ & $\begin{array}{c}20 \\
(83 \%)\end{array}$ & $\begin{array}{c}3 \\
(13 \%)\end{array}$ & $\begin{array}{c}1 \\
(4 \%)\end{array}$ & \\
\hline d & $\begin{array}{c}5 \\
(21 \%)\end{array}$ & $\begin{array}{c}15 \\
(62 \%)\end{array}$ & $\begin{array}{c}4 \\
(17 \%)\end{array}$ & \\
\hline & yes & no & & \\
\hline $\mathrm{e}$ & $\begin{array}{c}23 \\
(96 \%)\end{array}$ & $\begin{array}{c}1 \\
(4 \%)\end{array}$ & & \\
\hline
\end{tabular}

Observations:

a: child understood the functioning of the game

b: child mastered the ECPA menu and mask one marker at once

c: child used the snapshots of the plant exhibiting excesses or lacks of needs

$\mathrm{d}$ : child grabbed the main marker to observe the plant from different view points

e: child was concentrated during all the game

training period, and 2 children operated the menu with difficulties throughout the experiment. These children masked several markers at once, and the screen reversed image is another factor that slowed down the adaptation time to control the interface (cf. Fig. 1(a)).

According to the questionnaire: most children (22 over 24) had never been confronted with an AR application. However, all of them have completed the experiment successfully. 16 children stated that the interaction technique was easy or very 
easy, while 6 found this technique of an average difficulty. Only 2 children found the interaction method difficult or very difficult. Finally, 15 children found the introduction module easy or very easy, 8 of an average difficulty and 1 difficult. 5 children found the main module easy or very easy, 10 of an average difficulty and 9 difficult. This application seems to be of an average difficulty, with an easy part with the introduction module, and a challenge part with the main module, but the results may be in relation with the reverse image problem, and the multi covering problem.

\section{3) User Preferences, Enjoyment And Motivation:}

According to the observations: 23 children were concentrated during the experiment, and 1 remained very unfocused. An extension was added to each marker to allow taking it without covering key detection symbols. We observed that 5 children often grabbed the main marker to see the plant from different view points. 15 of them grabbed it sometimes and 4 never. It was a child initiative that contributed to user engagement and curiosity during the experiment. Furthermore 20 of them often used the snapshots of the plant exhibiting excesses or lacks of needs. That may be in relation with child interest for the real time virtual plant visual feedback.

According to the questionnaire: the time passed to complete the introduction module was adequate for 19 children, short for 4 and long for 1 . In the case of the main module, the time passed is perfect for 11 children, short or too short for 2 children, and long for 11 children. Finally, 17 children enjoy very much the introduction module, 6 enjoy it a little, and 1 does not like or dislike it. The main module is very appreciate by 19 children, appreciate by 3 children and 2 remain without an opinion. Finally, it seems that the child interest, motivation and enjoyment for our application and interface method is relevant. But to be more specific and formal, others advanced methods must be used like the Mehrabian Pleasure-Arousal-Dominance model for example.

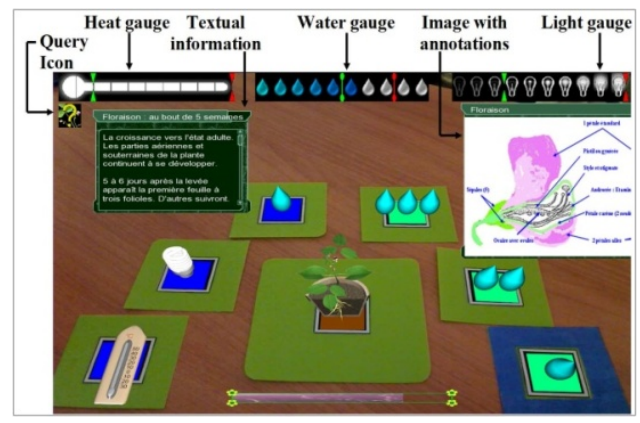

Fig. 10. VPFC with two added windows that provide information about the needs and the morphological aspects of the studied plant. ( Color Plate 12 )

\section{CONCLUSION AND PERSPECTIVES}

This paper presents an augmented reality Engine for the Construction of Pedagogical Applications (ECPA) that allows developing simple low-cost AR applications for classroom using non intrusive interfaces. A game called Virtual Plant For Children (VPFC) has been created and allows simulating and interacting with dynamic virtual plants generated with a Real Time Interactive L-system (RTIL-system). Twenty-four K4-K5 children were instructed to make the virtual plants grow by giving them water, heat and light, using an ECPA menu system. Results show that children complete the scenario quite easily with interest and enjoyment, in a short time corresponding to a classic time for computer learning session.

In the near future, we will complete VPFC graphical interface by adding pedagogical information (Fig. 10) and make an experiment about the learning notions acquired by the child during the game. Emotional and enjoyment reactions of child will be studied in more details, and the ECPA possibilities will be explored by developing other simple applications in other fields like mathematics or history.

\section{AKNOWLEDGMENT}

This work was supported by the General Council of Maine et Loire (France). We thank François-Xavier Inglèse for his contribution concerning the AR application development. We warmly thank our recently disappeared colleague Jean-Daniel Viemont, researcher at university of Angers (France) for the pedagogical content and botanical sheets about the Phaseolus Vulgaris. We also thank the director and teachers of the Saint-Antoine School of Angers for allowing us to carry out the experiment.

\section{REFERENCES}

[1] A. Johnson, M. Roussos, J. Leigh, C. Vasilakis, C. Barnes, and T. Moher. Nice project: Learning together in a virtual world, in Proceedings of the Virtual Reality Annual International Symposium, 1998, pp. 176-183.

[2] H. Taejin and W. Woontack. Garden alive: an emotionally intelligent interactive garden, The International Journal of Virtual Reality, 5(4), pp. 21-30, 2006.

[3] H. Kato and M. Billinghurst. Marker tracking and hmd calibration for a video-based augmented reality conferencing system, in Proceedings of the 2nd international workshop on Augmented Reality, 1999, pp. 85-94.

[4] P. Prusinkiewicz and A. Lindenmayer. The algorithmic beauty of plants, Springer Verlag, 1990-2004.

[5] J. Kim. Develop experience learning contents and research the application of a field based augmented reality, in Korea education and research information service (keris), 2005.

[6] J. Jung and J. Lee. Hangeul learning system, in Lecture Notes in Computer Science (including subseries Lecture Notes in Artificial Intelligence and Lecture Notes in Bioinformatics), vol. 5093, pp. 126-134, 2008.

[7] M. Billinghurst, H. Kato, and I. Poupyrev. The magicbook - moving seamlessly between reality and virtuality, in IEEE Computer Graphics and Applications, vol. 21, 2001, pp. 6-8.

[8] A. Dunser and E. Hornecker. Lessons from an augmented reality book study, in TEI 07 First International Conference on Tangible and Embedded Interaction, 2007, pp. 179-182.

[9] R. Grasset, A. Dunser, and M. Billinghurst. Edutainment with a mixed reality book: A visually augmented illustrative childrens' book, in Proceedings of the 2008 International Conference on Advances in Computer Entertainment Technology, 2008, pp. 292-295.

[10] S. ZhiYing and A. Cheok. Wlzqubestm a novel tangible interface for interactive storytelling in mixed reality, in ISMAR, 2007, pp. 9-10.

[11] H. Lee and J. Lee. Mathematical education game based on augmented reality, Lecture Notes in Computer Science (including subseries Lecture 
Notes in Artificial Intelligence and Lecture Notes in Bioinformatics), vol. 5093, pp. 442-450, 2008.

[12] J. Almgren, R. Carlsson, H. Erkkonen, J. Fredriksson, S. Moller, H. Rydgard, M. Osterberg, and M. Fjeld. Tangible user interface for chemistry education: Portability, database and visualization, in SIGRAD 2005. Linkoping University Electronic Press, 2005, pp. 19-24.

[13] A. Nischelwitzer, F. Lenz, G. Searl, and A. Holzinger. Some aspects of the development of low-cost augmented reality learning environments as examples for future interfaces in technology enhanced learning, Universal Access in Human-Computer Interaction. Applications and Services, vol. 4556, pp. 728-737, 2007.

[14] S. Oh and W. Woo. ARgarden: Augmented edutainment system with a learning companion, Lecture Notes in Computer Science (including subseries Lecture Notes in Artificial Intelligence and Lecture Notes in Bioinformatics), vol. 5080, pp. 40-50, 2008.

[15] S. Gilroy, M. Cavazza, R. Chaignon, S. Makela, M. Niranen, E. Andr, T. Vogt, B. M. Urbain, J and, H. Seichter, and M. Benayoun. E-tree: Emotionally driven rugmented reality art, in Proceedings of the 2008 ACM International Conference on Multimedia, with co-located Symposium and Workshops, 2008, pp. 945-948.

[16] M. Naud, P. Richard, and J. Ferrier. Augmented reality interaction techniques: design and evaluation of the flip-flop menu, in Proceedings of the 4th International Conference on Computer Graphics Theory and Applications, GRAPP 2009, 2009, pp. 345-352.

[17] L. Hamon, E. Richard, P. Richard, and J. Ferrier. Real-time interactive l-system, a virtual plant and fractal generator, in Proceedings of International Conference on Computer Graphics Theory and Applications GRAPP 2010, 2010, pp. 370-377.

[18] P. Favre, G. Guéritaine, R. Andrieu, R. Boumaza, S. Demotes, C. Fournier, G. Galopin, L. Huché-Thélier, P. Morel, and V. Guérin. Modelling the architectural growth and development of rosebush using l-systems, in Workshop on Growth Phenotyping and Imaging in Plants, 2007.

[19] D. Iordache and C. PRIBEANU. A comparison of quantitative and qualitative data from a formative usability evaluation of an augmented reality learning scenario, Informatica Economica Journal, 13(3), pp. 67-74, 2009.

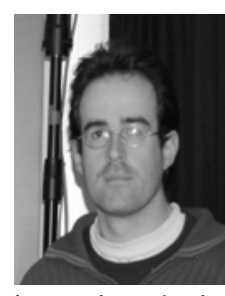

Ludovic Hamon was born in Luçon, France, in 1979. He received his BS and MS in Computer Science from the University of Nantes and Angers in respectively 2004 and 2005. Ludovic Hamon is currently PhD student at the university of Angers - ISTIA (Institut des Sciences et Techniques de l'Ingénieur d'Angers) and a member of the virtual reality team of the Laboratoire d'Ingénierie des Systèmes Automatisés (LISA), since march 2007. His research focuses on virtual reality, multi-modal interaction, physical rendering and real time 3D rendering.

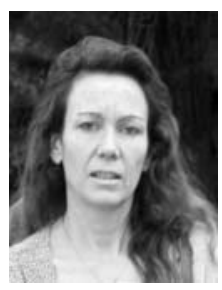

Emmanuelle Richard was born in Valenciennes, France, in 1966. She received his BS and MS in Chemistry from the University of Pierre et Marie Curie (Paris 6) in 1988 and 1989 respectively. She received a $\mathrm{PhD}$ in Materials Chemistry from the University of Paris 6 in 1996. Dr. E. Richard is currently assistant professor at the university of Angers - ISTIA (Institut des Sciences et Techniques de l'Ingénieur d'Angers) and is a member of the virtual reality team of the Laboratoire d'Ingénierie, des Systèmes Automatisés (LISA), since 2004. Her research focuses on virtual reality, multi-modal interaction and educational applications.

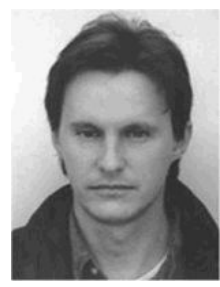

Paul Richard was born in Négrepelisse, France, in 1964. He received his BS and MS in Electronics and Automation from the University of Nice Sophia-Antipolis in 1990 and 1991 respectively. He received a $\mathrm{PhD}$ in Robotics from the University of Paris 6 in1996. Dr. P. richard is currently assistant professor at the university of Angers - ISTIA (Institut des Sciences et Techniques de l'Ingénieur d'Angers) and responsible of the virtual reality research activities of the Laboratoire d’Ingénierie des Systèmes Automatisés (LISA). For more than a decade, his research focuses on virtual reality, multi-modal interaction and human performance in virtual environments.

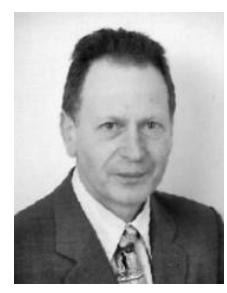

Jean-Louis Ferrier was born in Couiza, France, in 1947. Currently Professor of the university of Angers, he received the diploma of engineer from INSA Toulouse in 1969 and the PhD from the University of Angers in 1986. He spent two years as a control systems engineer at Motorola automotive division. He was the head of the Electrical and Computer Engineering Department of ISTIA (Institut des Sciences et Techniques de l'Ingénieur d'Angers) from 1989 to 1998. He was the founder and head of the Laboratoire d'Ingénierie des Systèmes Automatisés (LISA) whose topics are Control Engineering, Virtual Reality, Signal and Image processing, from 1987 to 2007 . His research has focused on many areas, including Automatic control, Computer engineering, Automation, Virtual reality. From 2000 to 2002, he was the Director of the graduate school of Angers - gathering the University PhD students. In 2002-2003 he was appointed as a Delegate of the French Ministry of Research and Technology. He is currently vice-president of the scientific council of the university of Angers. 